\title{
A construção da humanidade
}

Maria Helena Pires Martins

O artigo apresenta uma abordagem conceitual dos termos educação e cultura, sendo a primeira definida como processo de humanização do indivíduo e a segunda como atribuição de significado ao mundo e a nós mesmos. A autora amplia o significado de cultura inicialmente proposto, avançando sua argumentação a respeito das diferentes acepções do termo e postula que este pode ser entendido como: 1) uma resposta às necessidades e aos anseios humanos, modificando-se à medida que essas necessidades e anseios se alteram; 2) sentimento de pertença a um grupo ou comunidade que muitas vezes enseja a construção de identidades comuns e que se configura como base para o estabelecimento da comunicação entre pessoas de um mesmo grupo ou de grupos que se reconhecem diferentes entre si; 3) artes, patrimônio cultural material e imaterial. A educação, tanto a formal quanto a não-formal, apresenta uma relação intrínseca com esses diferentes sentidos de cultura, sendo não apenas responsável pela transmissão de manifestações culturais acumuladas por determinados grupos - do patrimônio cultural -, mas também assumindo a responsabilidade de estimular a criação. Tendo em vista o papel fundamental da educação em relação à cultura, a autora salienta a necessidade de transformar a escola num ambiente cultural plural em que os alunos possam vivenciar sua própria cultura e a de outros povos.

Palavras-chave: cultura; educação 


\section{The construction of humanity}

Maria Helena Pires Martins

This article presents a conceptual approach in terms education and culture, the former being defined as a process of humanization of the individual and the second one as the attribution of meaning to the world and to ourselves. The author expands the initially proposed meaning of culture, advancing her arguments on the different acceptations of the term and claims that it can be understood as: 1) an answer to human needs and expectations, modifying to the extent that these needs and expectations change; 2 ) the feeling that one belongs to a group or community that many times gives rise to the construction of common identities and that is configured as the base for the establishment of the communication between people from a same group or from groups that recognize to be different from each other; 3) arts, material and immaterial cultural assets. Education, both formal and informal, presents an intrinsic relationship with these different senses of culture, being not only responsible for transmitting cultural manifestations cumulated by certain groups - the cultural asset -, but also taking responsibility for stimulating creation. Considering the fundamental role of education in relation to culture, the author highlights the need for turning school into a plural cultural environment where students can experience their own culture and that of other peoples.

key words: culture; education 


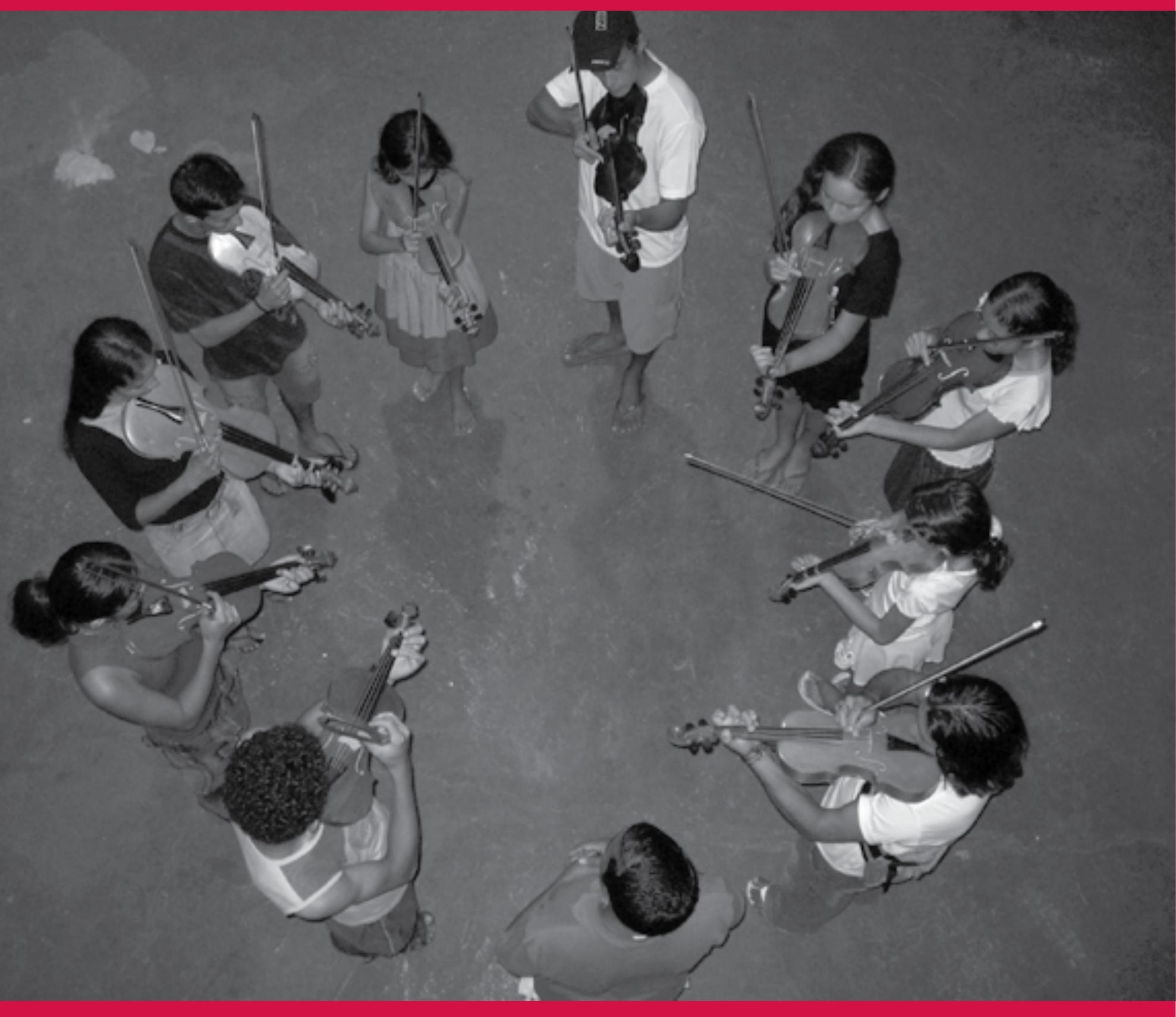




\section{A construção da MaRR HELENA PrRes MARTINS humanidade}

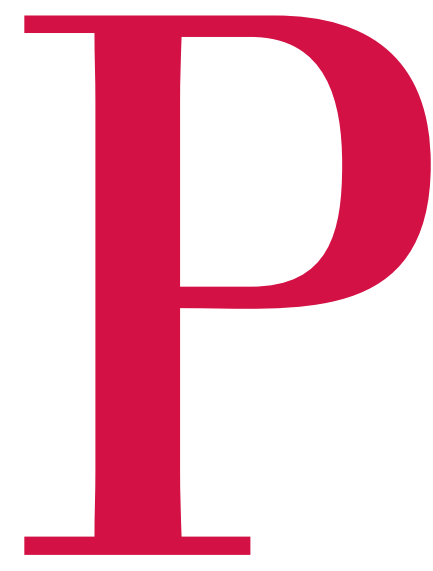

ara discutir o tema Educação e Cultura, a primeira questão que me ocorre é estabelecer as relações entre essas duas áreas. Elas são muito interconectadas e, por questões pedagógicas, separo uma e outra para falar uma coisa de cada vez.

A primeira questão nessa inter-relação é saber como conceituamos esses dois temas. Vou começar com uma conceituação muito geral: a de que educação é o processo de humanização do indivíduo. Dentro dessa grande generalidade, a cultura também é um processo de cultivo do ser - respeitando a raiz da palavra, que vem de cultivar - no seu processo de humanização.

De repente nos perguntamos: estamos falando da mesma coisa? Ambas são processos de humanização do indivíduo; mas a cultura é também atribuição de significados. Significados que nós damos ao mundo, significados que damos a nós mesmos.

A uma pedra, que poderíamos considerar uma coisa da natureza, quando nós nos sentamos sobre ela, já atribuimos a ela uma outra significação: a de assento. Se usarmos a pedra para jogar dentro d'água e ver formaremse aqueles círculos, podemos dizer que isso é uma brincadeira; se a utilizamos para jogar amarelinha, também estamos usando para brincadeira. Podemos usar a pedra para enfeitar o jardim, para decorar alguma coisa.

Enfim, são significados diferentes que damos à pedra, que é uma coisa da natureza, e da qual nós não podemos nos aproximar a não ser por meio da cultura. Esses significados são passados de geração em geração e muitas vezes são modificados ao longo do tempo.

* Maria Helena Pires Martins é filósofa, escritora e professora de Políticas Culturais da Escola de Comunicações e Artes da Universidade de São Paulo. Atualmente é coordenadora da Escola do Museu de Arte de São Paulo - MASP.

FOTO À ESQ.: PROJETO RABECAS DA AMAZÔNIA: PRESERVAÇÃO E ENSINO - ASSOCIAÇÃO BRAGANTINA DE MÚSICA - BRAGANÇA / PA - ACERVO CULTURA VIVA 
Quando eu digo que o ser humano passa por um processo de humanização, estamos partindo de uma visão muito específica, filosófica, de que o ser humano não vem pronto; ele se humaniza, se transforma em ser humano. Construímos nossa humanidade por meio da cultura e da educação - porque educação é um modo de nos inserirmos na cultura e de nos tornarmos seres humanos. É importante ter sempre em mente esta premissa fundamental de que o ser humano não está pronto quando nasce; ele se torna um ser humano.

Dentro desse contexto, para afunilar um pouco mais essa generalidade de que a cultura é um processo de humanização, vamos discutir um pouco a definição antropológica de cultura; a cultura como:

- um conjunto de idéias: tudo o que pensamos, escrevemos;

- a criação e organização de instituições que se concretizam e se realizam no concreto, no mundo real;

- ações humanas que se criam, se preservam ou se aprimoram por meio da comunicação e da cooperação entre os indivíduos em sociedade.

Nessa reflexão, há três verbos principais: criar, preservar e modificar:

- Em primeiro lugar, criamos cultura. Ela é uma criação humana; apenas os seres humanos criam cultura. É o que nos distingue dos outros animais.

- Em muitas instâncias, nós preservamos a cultura. Essa cultura não é só um patrimônio; ela precisa ser transmitida para que as gerações futuras sejam incluídas dentro da mesma cultura.

- Ao mesmo tempo, essa cultura pode sempre ser atualizada, modificada. Mesmo quando nos voltamos às coisas do patrimônio, ele não é o mesmo de quando foi criado. Ele é visto com os olhos do tempo presente e ressignificado em função disso.

\section{Permanência e mudança}

A cultura responde sempre a desejos e anseios humanos e às necessidades humanas e necessidades da comunidade. Por isso é diversificada.
Construímos nossa humanidade por meio da cultura e da educação porque educação é um modo de nos inserirmos na cultura e de nos tornarmos seres humanos. É importante ter sempre em mente essa premissa fundamental de que o ser humano não está pronto quando nasce; ele se torna um ser humano.

Em primeiro lugar, porque cada comunidade vai ter necessidades diferentes que vão desde a geografia, a economia, a história da comunidade. Ela vai apresentar desejos diferentes também.

Se desconsiderarmos um pouco os meios de comunicação de massa que, às vezes, tendem a homogeneizar esses desejos - a consumidora quer o cabelo que apareceu na novela tal, o consumidor deseja a roupa que apareceu em tal lugar -, as pessoas vão poder fazer o uso desses desejos de formas muito diferentes, mesmo com a influência dos meios de comunicação de massa.

Em segundo lugar, além da diversidade que isso proporciona, temos sempre uma dinâmica, porque as necessidades mudam e os anseios, também. Como a tradição, nesse sentido da cultura, vai enfrentar os desafios de um mundo novo, de necessidades novas, ela vai resultar nessa diversidade para os vários grupos sociais. Ao mesmo tempo, é preciso considerar que as 
mesmas necessidades podem requerer uma certa estabilidade.

Então, vamos ter uma tendência de reprodução da cultura, de manter a cultura um pouco mais estável, de fazer a mesma coisa que nossos pais e os nossos antepassados faziam.

Outras vezes, a necessidade é exatamente de mudança e nós temos que reestruturar a cultura em um novo mundo. As ideias novas, as técnicas novas, o estilo de vida novo nos obriga a adaptar a cultura e criar respostas diferentes para as nossas necessidades.

\section{Identidade e pertencimento}

\section{De um lado, a cultura é um cimento que mantém unidos}

os grupos e as comunidades; é aquilo que existe de comum e que nos liga. Mas, ao mesmo tempo, ela nos diferencia dos outros. Ela estabelece que a cultura desse grupo é diferente da cultura daquele grupo, apesar de haver sempre o fundo comum de determinado caminho nesse sentido da humanização.

Esse cimento, essa ideia de que existe algo comum, vai também construir o pertencimento. Como eu pertenço a uma comunidade ou um determinado grupo? Eu não preciso explicar o mundo para o outro porque essa cultura comum é uma base para nossa comunicação.

A cultura é ainda uma oportunidade de prazer, de autorreconhecimento e de autoprodução. A questão do autorreconhecimento é exatamente a ideia de que eu me vejo retratado na minha cultura. Existem outras culturas que eu digo: "não tem nada a ver comigo, aquilo não é comigo, não sou eu", mas, na minha cultura, eu tenho de me ver retratado - deve conter alguma coisa minha para que eu possa dizer que pertenço a esse grupo. A partir disso é que eu me identifico com a cultura.

Mais do que ter uma identidade de pertencimento, eu me identifico com os aspectos dessa cultura que tem várias facetas (religião - não importa se é o catolicismo, o budismo, os evangélicos -, time de futebol etc.). Eu me vejo representado em cada um desses grupos, eu me irmano e digo: "aqui tem alguma coisa que sou eu também, que é minha”, e é nesse momento que a gente pode falar de identidade ou identidades - as múltiplas identidades que temos de acordo com os papéis ou grupos variados nos quais vivemos.

A autoprodução vai nos levar outra vez para a questão da humanização. Se não nascemos prontos, enquanto seres humanos; se temos de nos produzir, nos fazer, nos tornar humanos, essa produção vai se dar por meio da cultura e por meio do social. É com o social que eu vou me tornar humano. Sozinho, isolado, eu não me torno humano. É nesse convívio, nessa troca, nesse embate, nesse reconhecimento de valores, de ideias que são comuns, que vou me tornando humano e, ao mesmo, descobrindo quem sou. Ao mesmo tempo em que produzo cultura, eu me produzo também e descubro quem sou.

\section{Arte e possibilidades do real}

\section{Para falar de prazer, vou abordar um pouco o sentido} estrito de cultura.

Em primeiro lugar, se tudo o que o ser humano faz é cultura, abrangemos uma área tão vasta que, dentro de um Ministério da Cultura, uma Secretaria da Cultura ou mesmo o trabalho dos produtores culturais, do pessoal que denominamos "o pessoal da cultura", fica imensa e difícil de ser administrada.

Em termos de secretarias, ministérios etc., vamos sempre constatar que a Secretaria de Cultura lida fundamentalmente com patrimônio e com artes. 0 patrimônio engloba uma série de itens: desde o patrimônio oficial - seja o patrimônio em pedra e cal, o patrimônio arquitetônico, seja todo o patrimônio material em termos de objetos, de adereços, partituras etc. - até o patrimônio imaterial que são festas, lendas, casos, modos de vida.

O patrimônio, tanto o oficial, que é o patrimônio do IPHAN, reconhecido, tombado etc., quanto o não oficial, que é o patrimônio mais próximo das pessoas, aquilo que dentro da sua comunidade conta uma história, tem 
uma importância para história daquela comunidade: aquilo que mantém a comunidade unida dentro de determinados valores, sejam eles festas, hábitos, não importa. É exatamente o que vem dos próprios grupos e que os próprios grupos valorizam e precisa ser cuidado e mantido.

Do outro lado, a gente tem todo o território das artes, e arte é aquilo que dá prazer. Não tem outra função mais importante para arte do que essa. Ela não é útil para coisa alguma, fora essa. Não é útil para tirar menino da rua, para me fazer ganhar status social. Durante muito tempo, a pessoa era culta porque tinha um acúmulo de conhecimentos e isso dava a ela um status social acima do resto dos mortais que não tinham um acúmulo de conhecimento específico.

Se pensarmos um pouco, a arte é gratuita; ela é aquele "a mais" que existe em nossa vida, mas é o "a mais" que nos torna mais humanos, é o "a mais" que enriquece nossa vida, que traz um novo conhecimento de mundo. Isso significa que posso sair da minha vivência de uma mulher que nasceu em São Paulo, em 1943, que viveu de determinada forma até hoje, e experimentar a vida no Amazonas, na África, na Austrália; experimentar a vida no mundo inteiro por meio das obras de arte.

Por meio da música, por exemplo. Aquilo que aquela música me traz é um determinado sentimento de mundo que está ligado a onde ela foi criada, como eu a ouvi. E isso eu posso ter sem precisar sair do meu lugar, ou sem ter que viver uma experiência que não é a minha. A arte proporciona essa possibilidade de você multiplicar sua vida, suas experiências e seu conhecimento. Mais do que qualquer coisa, isso acontece porque a arte não fala da realidade ("isto é assim").

Mesmo um documentário, que "teoricamente" estaria nos mostrando uma realidade, experimenta um pro- cesso particular de criação: qual história vai ser contada, quais depoimentos serão tomados e como serão editados, como serão os enquadramentos, como esses depoimentos vão ser encadeados. Pode-se utilizar uma linguagem contundente, agressiva; é possível colocar, lado a lado, duas pessoas com depoimentos completamente diferentes, uma contradizendo a outra. Nesse momento, está-se criando um determinado significado para esse documentário que vai muito além dos fatos que ele está mostrando. Ele tem uma mensagem, ele diz algo. Nenhum documentário é neutro.

Qualquer obra de arte, mais do que retratar a realidade, nos mostra possibilidades do real. A vida ou o mundo poderia ser assim. Inclusive a arte abstrata. É verdade que ela não está retratando; mas há uma questão de formas, de cores que, de repente, olhamos e, nesse momento, descobrimos uma nova possibilidade do real, que podemos trabalhar a partir daí, porque ela aciona nossa imaginação.

Uma das melhores coisas que podem acontecer na vida, além de viver a realidade, é poder imaginar outras possibilidades; isso é a mola da transformação do mundo. Isso tudo acontece de certa forma porque a arte não se dirige à razão especificamente. Ela se dirige muito mais ao sentimento, esse sentimento de mundo.

Não quer dizer com isso que eu deva, necessariamente e sempre, me emocionar com a arte, ter uma emoção de raiva, de riso etc. Não é por aí, porque a emoção rompe a estabilidade afetiva, uma vez que é uma agitação profunda. A arte é acolhida pelo sentimento, que é uma reação cognitiva, de reconhecimento de certas estruturas do mundo. 0 que percebemos na obra de arte é o sentimento de um mundo particular. É trazer esse conhecimento que não passou por aqui, mas veio por aqui antes. 
Uma das melhores

coisas que podem

acontecer na vida, além

de viver a realidade, é poder imaginar

outras possibilidades;

isso é a mola da

transformação do

mundo. Isso tudo

acontece de certa

forma porque a arte

não se dirige à razão

especificamente. Ela

se dirige muito mais

ao sentimento, esse

sentimento de mundo.

\section{Educação "bancária" e educação para a liberdade}

Feita minha "defesa" da arte, vamos passar para as questões da educação. Se temos, de um lado, uma cultura que precisa ser transmitida, passada adiante, porque é um conhecimento acumulado e não vamos ficar reinventando a roda a cada vez; de outro lado, precisamos da criação para poder não só adequar essa cultura às necessidades de hoje, como também inventar novos mecanismos, novas ideias, novas instituições etc.
Para que possamos lidar com o mundo atual, recorremos a Paulo Freire, que nos aponta dois tipos fundamentais de educação: uma educação bancária e uma educação para a liberdade.

A primeira teria por objetivo a manutenção do status quo; é a educação que eu ainda recebi, na qual decorávamos textos e números. Não era para inventar nada. Nesse sentido é que Paulo Freire dizia que era uma educação bancária porque era uma educação da acumulação. Era uma questão de você acumular dados, acumular informações, mesmo que essas informações não servissem para seu tráfego cotidiano, seja da vida com o outro, seja com a profissão.

Do outro lado, temos a educação para a liberdade. É a educação que nos permite passar da heteronomia para a autonomia. Da heteronomia, quando somos guiados por regras que vêm de fora, para a autonomia, em que construímos nossas regras e respondemos por elas. Não dá para construir e não se responsabilizar.

Essa passagem se dá em muitos níveis: há um nível que denominamos de cognitivo, que é quando somos capazes de pegar um texto - pegar outra vez a tradição, partir do que já existe - e reinterpretá-lo ou aplicá-lo a um outro contexto. Com isso, alargamos esse texto. Nesse momento, adquirimos a autonomia intelectual, atingimos o nível cognitivo.

Mas temos também a autonomia moral, que é uma questão da ação: a princípio, também somos regidos por regras dos outros. Na adolescência, costumamos questionar essas regras até transformá-las em nossas regras. Algumas delas nós vamos rejeitar, outras vamos aceitar como regras que conduzem ao bem comum, que levam a uma vida social mais harmoniosa, melhor, mais produtiva para todo mundo. Outras simplesmente jogamos fora. 
A mesma coisa vai acontecer com a cultura: eu posso simplesmente usufruir a cultura sem colocar nada de meu. Esse era o grande medo da Escola de Frankfurt: de que todo mundo ia virar um carneiro. 0 que estamos propondo é a educação para liberdade. Na verdade, é o uso dessa liberdade com responsabilidade. Vamos não só transmitir cultura, como também criar cultura, tanto no sentido da reinterpretação do que nos é dado e nós criamos novos significados, quanto a criação do nada, criação de novos produtos, mídia, conceitos etc.

\section{Educação formal e não formal}

\section{Temos, ainda, dentro dessa relação entre educação}

e cultura, a questão dos tipos de educação. Temos a educação não formal, que vai se dar na família, na vizinhança, entre grupos de amigos, grupos organizados da sociedade civil, na comunidade, e que pode ser dar, também, em cursos, leituras etc. A educação através de livros é uma educação não formal. Você vai lendo, vai se educando a partir desses livros, mas o autor não está ali para dizer se é assim ou assado.

Do outro lado, contamos com a educação formal, aquela que acontece na escola, regida por leis, decretos, regras; tem número " $x$ " de dias letivos; a aula começa aqui, termina ali; tem que dar $75 \%$ da matéria; agora tem livrinho...

Como fica a cultura na educação não formal? Já falamos que há a necessidade dessa transmissão da cultura que vem primeiro: a família, os amigos, a vizinhança, a comunidade... Esse conceito antropológico de cultura acontece por meio da educação não formal. São os modos de viver, o saber fazer que aprendemos dentro de casa, seja cozinhar, não cozinhar, arrumar a cama ou não, fazer isso dessa ou daquela forma, comer, juntar tais alimentos, não juntar determinados alimentos. Tudo nós aprendemos no seio da família.

Depois, mais tarde, com os amigos, com a vizinhança, ampliamos esses horizontes. Até a fala é aprendida, em primeiro lugar, no seio da família. A gente vem com um vocabulário, com os modos de construir a frase que ouvimos na nossa família e depois, também, na vizinhança, com os amigos, na comunidade. Até a educação da sensibilidade começa aí.

Se a mãe cantava, embalava seu filho cantando, isso já vai ficando. Se é uma família que ouve muita música, se canta muito, se mexe com cores ou se gosta de fazer

\author{
fundamentalmente, \\ tem que promover, \\ oferecer esses espacos \\ para que a cultura e a \\ educação deem a mão \\ e possam seguir juntas \\ na formacão de um \\ indivíduo mais rico, \\ acima de tudo, mais \\ feliz e com maiores \\ possibilidades de atuar \\ na transformação da \\ sociedade.
}

papel desse ou daquele - pessoas que, quando vão relatar um caso, fazem as várias vozes, fazem os vários personagens e tudo isso: em cada uma dessas situações, a criança está educando sua sensibilidade dentro de determinadas linguagens artísticas. Esse aprendizado na educação não formal é, em um primeiro momento, por imitação, por tentativa e erro, por prêmio e castigo.

Depois, existe um momento em que se pode fazer cursos que não sejam dentro da escola formal, estágios. Eu fiquei procurando uma palavra para o "aprendiz". Quero me referir àquele aprendizado que se dá com um mestre, em um ateliê ou oficina.

Nesses lugares, de uma forma mais estruturada, mais organizada do que o aprendizado na família, vamos ter uma educação da sensibilidade, a educação que eu chamo educação do corpo, que é educação da mão, se for na pintura, educação do ouvido, educação do corpo no espaço - qual o espaço que podemos ocupar no mundo e como vamos nos deslocar dentro desse espaço. Ao lado dos ateliês, temos também cursos livres que se voltam mais para a educação da mente: são cursos mais teóricos que apresentam técnicas, materiais, processos do fazer, além de história da arte, por meio de discussões e não “com a mão na massa”. A cultura está absolutamente presente na educação não formal desde o momento que nós nascemos. 
Na educação formal, é onde se dá o aprendizado da linguagem verbal que vai nos abrir as portas do mundo humano e também da poesia, da literatura. Mesmo a cultura estando dentro da escola, vamos dizer que talvez essa educação, em termos da cultura, no sentido mais estrito, não está. 0 professor tem dificuldade de lidar com essas outras linguagens que não aquelas com as quais ele tem alguma relação. Ele foi treinado, capacitado a lidar com Matemática, Geografia, História, mas a parte das artes fica numa aula específica e com o menor número possível, porque assim os alunos não ficam longe das "coisas importantes". E arte não entra em exames, em vestibular, não é questionada de jeito nenhum. De maneira que, normalmente, na maior parte das escolas, o que vemos é isto: a arte, essa parte extremamente importante da cultura, em sentido estrito, é extremamente desvalorizada.

0 que temos como necessidade na escola?

Principalmente, a criação de um ambiente cultural plural em que os próprios alunos tragam suas culturas de origem e possam discutir, mostrar sem serem ridicularizados, sem precisarem se encaixar dentro de uma cultura única, que é a cultura escolar, e possam vivenciar outras culturas, sobre as quais eles tenham muita curiosidade. Por exemplo, o hip hop: eu não sei o quanto ele está dentro da escola nesse sentido mais formalizado, mas no sentido informal ele certamente estará.

Segundo: precisamos ter oportunidades de criação cultural, multiplicar essas oportunidades de procurar, de fazer, pesquisar e de fazer arte - fazer muita arte dentro da escola em "todos os sentidos", algo que pode até ser encarado como: "você está fazendo arte, não está fazendo nada sério". A educação da sensibilidade só se dá se nós experimentarmos materiais, se brincarmos com esses materiais.

0 brincar faz parte dessa educação. Deixar essa experiência, saber o que dá certo e o que não dá certo. A oportunidade de discussão da cultura também é muito importante: ter debate sobre cultura, trazer pessoas de formações muito diferentes, de culturas muito diferentes, para conduzir esses debates, para mostrar essas culturas, trazê-las todas à luz.

$E$, finalmente, a oportunidade de pesquisa, na qual entra a questão da história da arte, das linguagens, das técnicas. Deixar que essas pesquisas sejam feitas pelos alunos para que eles possam ter uma verdadeira dimensão do que é a linguagem que eles escolheram ou as outras linguagens da arte, até para dizer: "acho que eu quero fazer isso", "acho que eu me encaixo aqui, eu me identifico com esse tipo de linguagem para me expressar e não com outras".

A escola, fundamentalmente, tem de promover, oferecer esses espaços para que a cultura e a educação deem a mão e possam seguir juntas na formação de um indivíduo mais rico, acima de tudo, mais feliz e com maiores possibilidades de atuar na transformação da sociedade.

O que temos como necessidade na escola? Principalmente, a criação de um ambiente cultural plural em que os próprios alunos tragam suas culturas de origem e possam discutir, mostrar sem serem ridicularizados, sem precisarem se encaixar dentro de uma cultura única, que é a cultura escolar, e possam vivenciar outras culturas, sobre as quais eles tenham muita curiosidade. 


\section{Arte como instrumento de transversalidade}

MônICA Hoff *

Arte, educação e campos do conhecimento.

\section{Embora tenha o público escolar como principal objeto} de seu trabalho, o Projeto Pedagógico da Fundação Bienal do Mercosul não trabalha, exatamente, com o ensino da arte nas escolas. Suas ações e seu pensamento se estabelecem no âmbito das micropolíticas situacionais, locais e regionais, a partir de experiências informais. Cada ação é definida a partir do estudo caso a caso.

Essas experiências, embora envolvam, na maioria das vezes, professores e estudantes, acontecem também com redes comunitárias, a partir de experiências colaborativas. 0 foco do projeto pedagógico não é o lugar no qual as relações são estabelecidas, e sim as próprias relações. São os agentes (professores, estudantes, comunidade) que movimentam o projeto e que fazem dele um processo dinâmico e transversal.

O projeto pretende subsidiar o professor em sua prática e em suas investigações diárias; ao mesmo tempo, se propõe a dar conta de uma série de outras atividades que giram em torno da comunidade, objetivando uma formação mais ampla e experimental.

Não acreditamos na arte como disciplina, e sim como ferramenta de atravessamento. Reconhecemos o importante papel político da criação da disciplina de Educação Artística para o currículo escolar - esse movimento é inquestionável e devemos muito a ele. No entanto, defendemos que o modelo tradicional não funciona mais.

Dar à arte a insígnia de disciplina é transformá-la em uma coisa que ela não é. Limitar a experiência artística, esse processo crítico e poético, ao formato de uma disciplina parece contrariar as premissas da própria arte. $\mathrm{E}$, por isso, buscamos, cada vez mais, no projeto pedagógico, fazer uso de metodologias artísticas (com forte ca-

\footnotetext{
* Mônica Hoff é coordenadora executiva do Projeto Pedagógico da
} Fundação Bienal do Mercosul. pital pedagógico) para desenvolver ações experimentais e informais com o público escolar.

No que se refere às referências conceituais, o projeto pedagógico não segue uma linha única e rígida. Com a realização, a cada dois anos, de novos projetos curatoriais, em razão das mostras, o projeto pedagógico é obrigado a se repensar e a se propor novas miradas e metodologias.

Assim, ao invés de uma linha única e fechada, trabalhamos a partir de diferentes ideias e autores que somados nos possibilitam um "outro" olhar sobre a arte, a educação e seus cruzamentos com diferentes campos de conhecimentos. Alguns dos autores com os quais nos identificamos: Paulo Freire, Jacques Rancière, Nicolas Bourriaud, Luiz Camnitzer e Marcos Villela.

Compartilhar saberes é uma das nossas principais propostas, considerando sobretudo que o contato de crianças e adolescentes com a produção artística é a própria valorização de uma cultura estética mais democrática. Nesse processo, a democratização acontece - seja o movimento em pequena ou grande escala. Possibilitar às crianças e adolescentes o contato com a produção artística é transformar o contato em experiência concreta; é abrir espaço para novas narrativas, novos olhares, tomadas de decisão até então impensadas e, sobretudo, para o compartilhamento de saberes.

\section{A arte atravessa e é atravessada}

Luiz Camnitzer, curador pedagógico da 6a Bienal do Mercosul, costumava dizer que era preciso ver a arte como educação e a educação como arte. Ou seja, a arte contendo em si um forte capital pedagógico e a educação entendida como potência poética e crítica.

Ao entender a arte como ferramenta e não como disciplina, podemos dizer que ela atravessa os processos de educação em todos os seus movimentos. A arte con- 
temporânea, por exemplo, que muitas pessoas dizem não entender, é matéria do hoje, do que vivemos no nosso dia-a-dia e, como tal, se alimenta dos mais diversos saberes e campos de conhecimento para existir - atravessa e é atravessada.

Ao mesmo tempo, sabemos que a educação é cada vez mais transversal, espontaneamente transversal, embora muitos não percebam. Em 2009, não há mais lugar para instituições e metodologias rígidas de ensino: a escola do século XXI é um espaço de experiência comunitária aberta aos diferentes saberes e metodologias.

Não podemos esquecer que, na escola, se vai ao dentista, se faz pré-natal, participa-se de oficinas de culinária, de capoeira, de marcenaria; se constroem sites e blogs, se dança e, também, se tem aula. Nessa escola, não existem apenas alunos e professores: há famílias inteiras, clubes de mães, times de pais, festas de bairro, missa e consulta médica.

A escola é palco de manifestações, sede de reuniões e espaço de exposição. É lugar de democratização de saberes. Não é por nada que as próprias experiências artísticas estão cada vez mais se estabelecendo em âmbito colaborativo, através de redes e vínculos sociais.

Nosso trabalho principal é sensibilizar crianças, adolescentes e jovens para as artes, falando a língua deles, propondo discussões inteligentes, não subestimando a sua capacidade, reciclando-se constantemente e, sobretudo, gerando ações interessantes para eles. As crianças, adolescentes e jovens lidam e se relacionam com a arte de uma maneira muito mais poética e sem preconceitos que os adultos.

$\mathrm{Na}$ nossa visão, professores e alunos formam um conjunto homogêneo, integrado. Tanto tanto professor quanto aluno são mediadores e detentores de saberes e ambos têm autonomia para se movimentar livremente em relação à arte.

No entanto, num sentido mais específico de mediação (no processo educativo, por exemplo), eu diria que o professor tem papel fundamental nessa relação, pois é dele a responsabilidade primeira de apresentar, despertar e seduzir. 0 encantamento provocado no aluno decorre, muitas vezes, da sedução do professor.

No entanto, não é dele a responsabilidade final. A mediação é um caminho de mão dupla, que pressupõe uma relação. E uma relação, por sua vez, pressupõe a participação de, pelo menos, dois elementos, dois pensamentos ou duas pessoas.

\section{Residências artísticas para professores e moradores}

As Formações de Professores são pensadas e construídas a muitas mãos. A metodologia é gerada a partir de avaliações de todas as ações do projeto pedagógico, do feedback dos professores e de discussões em grupo: trabalhamos com uma equipe multidisciplinar da qual fazem parte conteúdos das áreas de educação, artes visuais, literatura, filosofia, teatro e música.

Por exemplo, em 2007, iniciamos o processo de formações de professores no interior do Rio Grande do Sul e, em 2008, voltamos a essas cidades para uma nova formação, com conteúdo mais amplo e transdisciplinar. Isso foi possível porque analisamos o registro deixado pelos professores na avaliação feita em 2007. Com o tempo, aprendemos a importância de medir nossas ações para então estabelecer novas ações.

Até o momento, realizamos dois ciclos de formações de professores, em Porto Alegre e em pelo menos 40 cidades do interior do Estado. A primeira formação tinha como base os assuntos abordados pela 6 ${ }^{\mathrm{a}}$ Bienal do Mercosul; a segunda, desvinculada das mostras, pois aconteceu em 2008, projetou uma nova discussão, que possibilitava aos professores entender certas transições artísticas e relacioná-las com a contemporaneidade, a partir de recortes e períodos anteriores.

Os encontros, normalmente, têm duração de oito horas (ou um dia inteiro de trabalho) e são divididos em dois momentos: um mais teórico, na parte da manhã, em que o grupo participa junto; e outro, à tarde, em que o grupo se divide para participar de diferentes oficinas e discussões. Cada professor participa de, pelo menos, duas oficinas por encontro.

Em 2009, junto à $7^{\underline{a}}$ Bienal, as Formações de Professores ganharam uma nova cara e acabaram se transformando num Programa de Residências de artistas chamado Artistas em Disponibilidade: a educação como espaço para o desenvolvimento de micropolíticas experimentais.

Esse programa reuniu 14 artistas, em 12 projetos, que realizaram residências artísticas em mais de 20 cidades do Rio Grande do Sul. Ele se propunha dar continuidade às formações de professores através da tradução de projetos artísticos com forte capital educativo para um contexto socioeducativo. Nesse trabalho, em vez de envolver somente professores, acabamos mobilizando comunidades inteiras. 
1 . S I TI

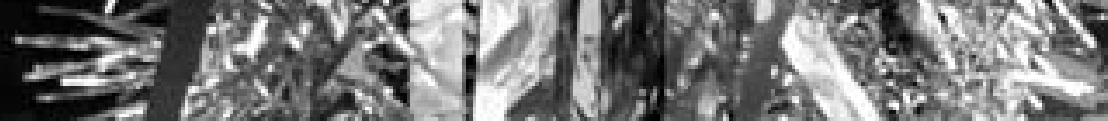
CBys

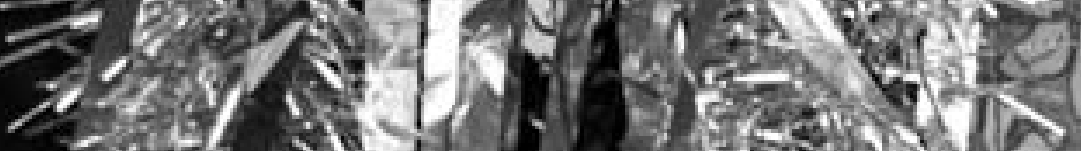

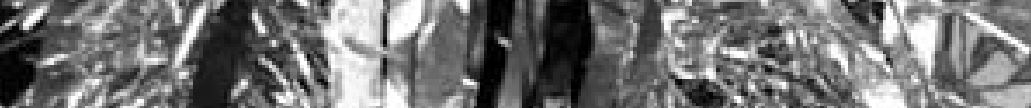
3 in a d E 301. a gowis 7 mas rignis i.

1 a)
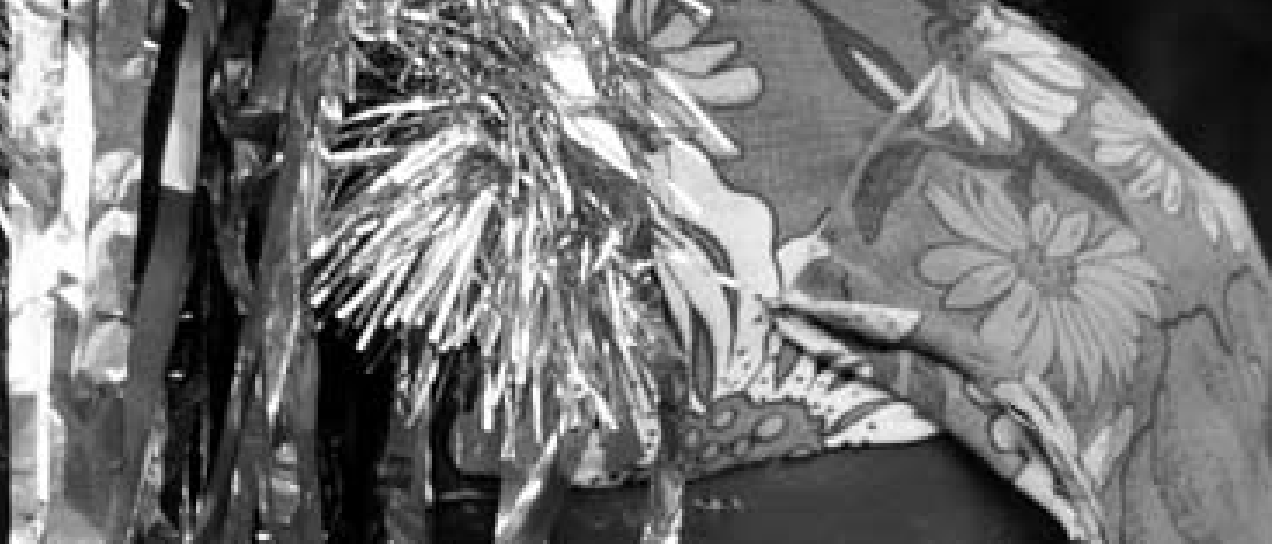

Q.

is: ,

pis

(3.). की

siogte<smiles>C1CC2CC3CC(C3)C(C1)C2</smiles>

1. (1)

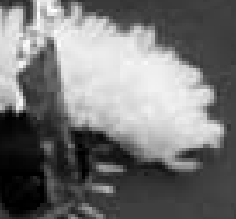

$y^{1}=-2$

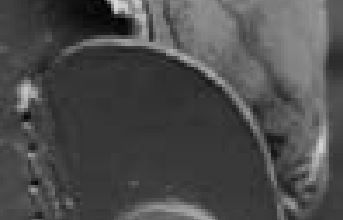

int

14

4

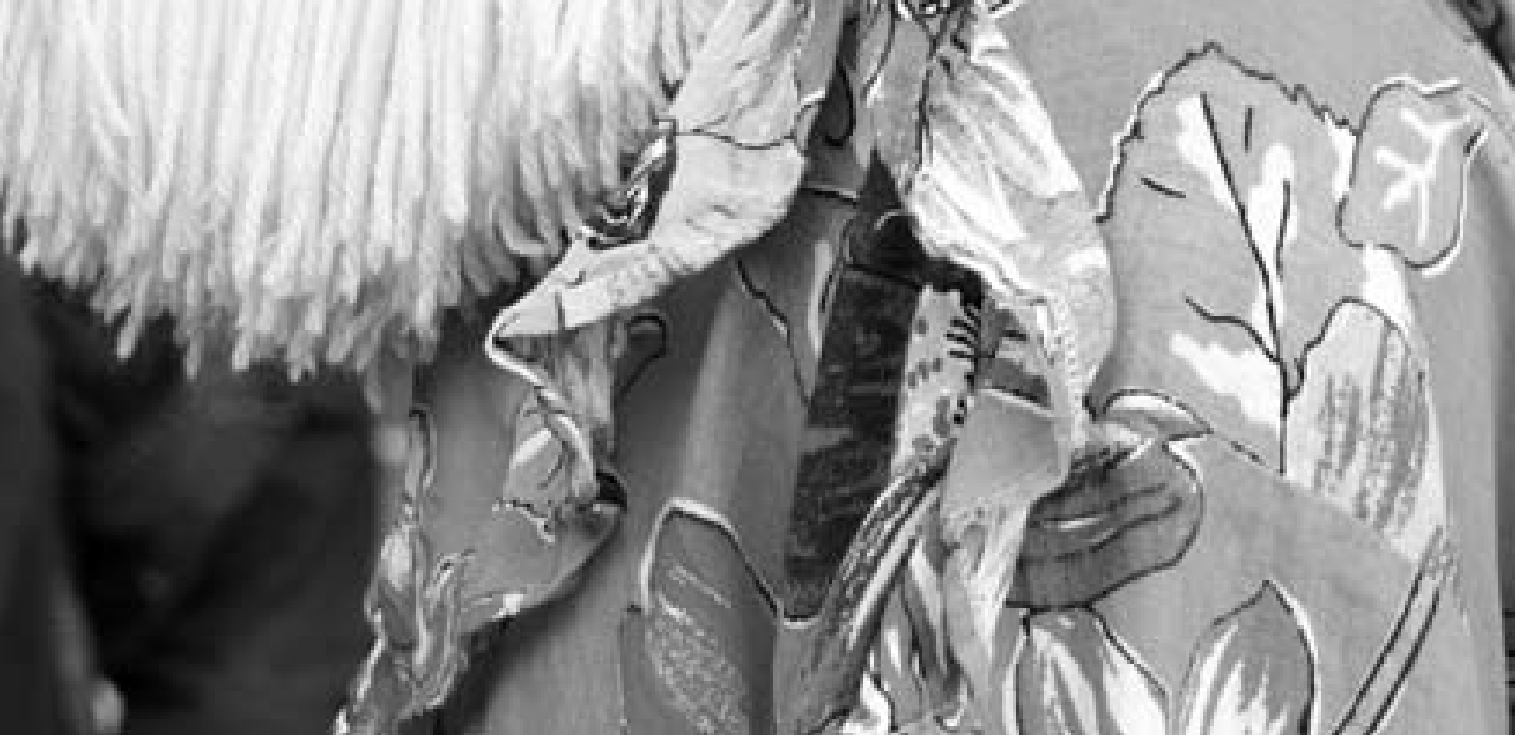

